\title{
ARKETIPE DALAM KUMPULAN CERITA RAKYAT OGAN KOMERING ILIR DAN IMPLEMENTASI PEMBELAJARAN BAHASA INDONESIA
}

\author{
Alia $^{1)}$, Tri Wulan Dari ${ }^{2)}$ \\ 1) 2) Program Studi Pendidikan Bahasa Indonesia \\ Universitas Islam Ogan Komering Ilir Kayuagung \\ 1) alia_dedho@yahoo.com, ${ }^{2)}$ triwulandari1043@gmail.com
}

\begin{abstract}
Abstrak
Penelitian ini bertujuan untuk mendeskripsikan arketipe dalam kumpulan cerita rakyat Ogan Komering Ilir dan implementasi pembelajaran bahasa Indonesia di SMA. Pendekatan yang digunakan ialah kualitatif dan metode deskriptif analisis. Dalam analisis ini menggunakan teori Carl Gustav Jung, yaitu arketipe dalam ketidaksadaran kolektif yang meliputi arketipe pesona (topeng), bayangan (shadow), anima, animus, ibu agung (great mother), orang tua yang bijak (wise old man), hero, dan diri (self). Hasil analisis diperoleh tujuh arketipe dari lima cerita rakyat, yaitu Putri Jari Sakti terdapat satu arketipe, Cinta Juliah Putri Ningrat terdapat lima arketipe, Si Seman Lempuing terdapat empat arketipe, Putri Gelam terdapat empat arketipe dan Keadilan Bagi Pangeran Batun tiga arketipe. Sementara itu, dalam pembelajaran bahasa Indonesia prosa lama ini bisa diadopsi sebagai materi pelajaran, karena setiap cerita lama terdapat bayangan-bayangan leluhur yang disebut dengan arketipe yang muncul dalam ketidaksadaran kolektif pada setiap manusia.
\end{abstract}

Kata kunci: arketipe, cerita rakyat, implementasi, pembelajaran

\section{PENDAHULUAN}

Pada umumunya manusia menggunakan kata-kata untuk berinteraksi secara lisan ataupun tertulis dalam mengungkapkan hal yang akan disampaikan. Bahasa yang digunakan oleh manusia dipenuhi simbol-simbol yang tidak jarang digunakan untuk tanda atau gambar yang tidak sepenuhnya memiliki makna. Bahasa ialah sebuah sistem atau simbol bunyi yang manasuka sehingga setiap orang dapat berkomunikasi (dalam Noermanzah,
2020, h. 3). Bahasa apabila dipenuhi dengan simbol-simbol, baik istilah, nama maupun gambar yang biasa digunakan dalam keseharian, akan memiliki makna yang nyata, seperti contoh patung pahlawan yang dikenal tetapi tidak diketahui makna yang terkandung dalam patung itu.

Hal di atas dapat dikatakan sebagai ketidaksadaran kolektif. Ketidaksadaran kolektif diartikan sebagai ketaksadaran yang tertanam dari ingatan-ingatan masa lampau nenek moyang, serta berhubungan 
dengan pikiran, perasaan, dan apa yang dilakukan seseorang. Selain itu, ketidaksadaran sering dihubungkan dengan kepercayaan, mitos, maupun legenda (Matthew dalam Septiarini dan Sembiring, 2017:81). Maka, ketidaksadaran kolektif ini mengacu pada leluhur di masa lampau yang diturunkan secara turun-temurun dan setiap manusia memiliki ketidaksadaran kolektif. Adapun isi utama yang ada dalam ketiksadaran kolektif adalah arketipe. Arketipe ini berasal dari leluhur yang diturunkan secara turun temurun berupa bayangan-bayangan leluhur yang berakar dari tidaksadaran kolektif.

Menurut Jung (dalam Syahdi, 2016:188), bahwa akar dari suatu arketipe adalah dalam alam "bawah sadar kolektif" umat manusia. Hal itu disebabkan bawah sadar manusia mengacu pada kehidupan. Dapat dikatakan arketipe ini muncul dalam pikiran alam bawah sadar manusia. Ketidaksadaran kolektif yang diturunkan dari satu kegerasi ke generasi berikutnya berada dalam situasi dan waktu yang dipengaruhi oleh pengalaman generasi terdahulu. Dengan demikian, ketidaksadaran kolektif pada manusia mempunyai kecenderungan yang diturunkan dalam kehidupan manusia, serta mengacu pada setiap individu.

Berhubungan dengan karya sastra, arketipe ini juga sama halnya dengan cerita-cerita masa lalu dan diwariskan oleh leluhur, salah satunya yaitu cerita rakyat. Cerita rakyat diartikan sebagai ungkapan folklore di dalam suatu masyarakat melalui bahasa tutur yang berhubungan langsung dengan berbagai aspek budaya dan susunan nilai sosial.

Cerita rakyat diwariskan
secara turun-temurun dari satu
generasi ke generasi berikutnya
secara lisan Hutomo (dalam Samardi,
2009, h. 26). Cerita rakyat menggambarkan sebuah cerita dari zaman dahulu yang ada dalam kalangan masyarakat dan merupakan bagian dari sastra lisan yang diwariskan secara turun-temurun melalui mulut ke mulut.

Cerita rakyat OKI termasuk salah satu cerita rakyat yang dialami oleh masyarakat terdahulu. Selanjutnya, diimplementasikan terhadap karya sastra berbentuk 
prosa. Selain itu, dapat juga dikemas sebagai pertunjukan drama atau diproduksi dalam bentuk film. Apabila dihubungkan dengan kurikulum pendidikan tingkat Sekolah Menengah Pertama, cerita ini ditemukan dalam pembelajaran bahasa Indonesia dan termasuk kategori pembelajaran sastra.

Kajian terdahulu yang sesuai dalam penelitian ini, yakni yang dilakukan oleh Syahdi. Dalam hal ini menganalisis arketipe karakter dan arketipe simbol. simpulannya ada empat arketipe karakter, yaitu The Innocent, The Hero, The Wise Old Man, and The Ruler, dan empat simbol yaitu The Color, The Tree and The Bow, The Numbers, and The Horse. Kemudian, penelitian dari Martina dengan judul "Analisis tokoh Mika dalam novel Kapak karya Dewi Linggasari menurut perspektif Jung: sebuah kajian psikologi sastra". Dari hasil analisis psikologi terhadap tokoh Mika dalam Novel kapak dengan menggunakan teori arketipe Carl Gustav Jung tidak lepas dari hasil analisis struktural. Penelitiannya menganalisis unsur arketipe teori Carl Gustav Jung yaitu pesona (topeng), bayangan (shadow), anima, animus dan diri (selft).

Dilihat dari kedua hasil penelitian di atas, ada perbedaan yang terletak pada hasil analisis yang dilakukan. Pada penelitian pertama menganalisis mengenai karakter dan simbol, sedangkan yang kedua menganalisis bentuk arketipe yaitu pesona (topeng), bayangan (shadow), anima, animus, dan diri (self). Dan peneliti tertarik untuk melakukan penelitian dengan memilih teori Carl Gustav Jung yang berjudul "Arketipe dalam Kumpulan Cerita Rakyat Ogan Komering Ilir dan implementasi dalam pembelajaran bahasa Indonesia di SMA". Alasan penulis memakai teori ini karena sangat cocok untuk mengkaji kumpulan cerita rakyat Ogan Komering Ilir dengan teori Aketipe Carl Gustav Jung mengenai struktur ketidaksadaran kolektif.

\section{METODE PENELITIAN}

Penelitian ini menggunakan pendekatan kualitatif. Metode yang digunakan adalah metode deskriptif analisis. Metode ini memberikan gambaran secara objektif tentang 
keadaan sebenarnya dari objek yang sedang diselidiki, untuk mendeskripsikan arketipe pesona, bayangan, anima, animus, Ibu, Orang Tua, Hero dan Self

Sumber data berupa buku kumpulan cerita rakyat Ogan Komering Ilir, yang diterbitkan oleh Dinas Pariwisata Kabupaten Ogan Komering Ilir, dicetak oleh CV. ADI JAYA UTAMA. Hak cipta C 2007, cetakan I, Desember 2007, dan tebal buku berjumlah 91 halaman serta terdapat 6 cerita rakyat, yaitu Putri Jari Sakti, Si Seman Lempuing, Puyang Rasyid dan Keris Saktinya, Cinta Juliah Putri Ningrat, Keadilan Bagi Pangeran Batun, dan Putri Gelam.

Teknik analisis data yang dilakukan dengan mengidentifikasi keseluruhan isi kumpulan cerita rakyat yang dipilih, mengklasifikasi data yang didapat dengan teori yang digunakan, dan mendeskripsikan hasil data yang didapat. Bentuk arketipe yang akan dianalisis adalah pesona, bayangan, anima dan animus, ibu Agung (great mother) dan hero dalam kumpulan cerita rakyat Ogan Komering Ilir dengan teori arketipe Carl Gustav Jung.

\section{PEMBAHASAN}

Pada hasil dan pembahasan, yang bahas dalam penelitian ini adalah bentuk arketipe dalam kumpulan cerita rakyat Ogan Komering dan implementasi pembelajaran bahasa Indonesia di SMA. Dari hasil penelitian, terdapat tujuh bentuk arketipe dan lima cerita rakyat. Berikut ini hasil analisis bentuk arketipe dalam cerita rakyat sebagai berikut.

\section{Tabel 4.1 Hasil Analisis Arketipe dalam Kumpulan Cerita Rakyat Ogan} Komering Ilir

\begin{tabular}{lrll}
\hline No. Judul Cerita & \multicolumn{1}{c}{ Aspek Arketipe } & \multicolumn{1}{c}{ Hasil Analisis } \\
\hline 1. Putri Jari Sakti & 1) Pesona (Topeng) & a. Terdapat satu arketipe \\
& & b. Terdapat empat kutipan \\
& & arketipe pesona (topeng) \\
& & c. Bentuk arketipe Pesona
\end{tabular}


terdapat pada tokoh Putri

Jari Sakti

2. Cinta Juliah 1) Pesona (Topeng) a. Terdapat lima bentuk Putri Ningrat

2) Bayangan arketipe

(Shadow)

b. Terdapat tujuh kutipan

3) Anima

c. Pada ke lima bentuk arketipe

4) Ibu Agung terhadap tokoh Juliah, Ibu

5) Orang Tua yang Janan, Gadis Desa, Pak Bijak Kalung, Tetua Kampung

$\begin{array}{lll}\text { 3. Si Seman 1) Pesona (Topeng) } & \text { a. Terdapat empat bentuk } \\ \text { Lempuing } & \text { 2) Bayangan } & \text { arketipe } \\ & \text { (Shadow) } & \text { b. Terdapat enam kutipan } \\ & \text { 3) Anima } & \text { c. Terdapat tokoh Si Seman } \\ & \text { 4) Diri (Selfi) } & \text { dan Depati Deris }\end{array}$

4. Putri Gelam
1) Pesona (Topeng)
a. Terdapat empat bentuk
2) Bayangan arketipe
(Shadow)
b. Terdapat tujuh kutipan
3) Anima
c. Terdapat tokoh Raja Awang,
4) Diri (Selfi) Pangeran Tapah Lanang, Saudara tiri Pangeran Tapah, dan Putri Gelam

\begin{tabular}{llll}
\hline 5. Keadilan bagi 1) Pesona (Topeng) & a. Terdapat tiga bentuk \\
Pangeran Batun & 2) Bayangan & arketipe \\
& (Shadow $)$ & b. Terdapat enam kutipan \\
& 3) Hero & c. Terdapat tokoh Cik Ayu, \\
& & Pangeran Mat dan Ratu \\
& & Wilhelmina
\end{tabular}


Berdasarkan hasil analisis di atas, dari hasil yang dilakukan hanya lima cerita yang terdapat arketipe, yaitu Putri Jari Sakti, Cinta Juliah Putri Ningrat, Si Seman Lempuing, Putri Gelam, dan Keadilan bagi Pengeran Batun. Alasan mengapa cerita rakyat mengenai Puyang Rasyid dan Keris Saktinya tidak terdapat arketipe, karena dalam cerita ini tidak ada yang menunjukkan arketipe seperti arketipe pesona (topeng), bayangan (shadow), anima, animus, ibu Agung (great mother), wise old man, hero dan self. Dapat dilihat dalam penelitian sebelumnya bahwa arketipe memiliki delapan bentuk berdasarkan ketidaksadaran kolektif.

Arketipe pada penelitian sebelumnya menganalisis mengenai novel, sedangkan pada penelitian ini peneliti mendeskripsikan arketipe dalam kumpulan cerita rakyat Ogan Komering Ilir, sehingga yang membedakan penelitian terdahulu terletak pada bentuk arketipe.

Berdasarkan hasil analisis yang berkaitan dengan cerita rakyat yang berhubungan dengan pembelajaran. Pembelajaran bahasa Indonesia di sekolah yang dipelajari juga berkenaan dengan cerita rakyat. Dalam pembelajaran bahasa Indonesia, cerita rakyat termasuk pembelajaran sastra di sekolah yang sudah ditetapkan dalam kurikulum 2013 revisi dan telah dicantumkan dalam silabus dan RPP. Dengan adanya sebuah pembelajaran sastra di sekolah peserta didik dapat mengapresiasi sastra dalam membaca, menulis, mendengarkan, dan dapat memahami karya sastra. Dengan begitu, peserta didik dapat mempelajari pembelajaran sastra di sekolah agar tercapainya tujuan pembelajaran.Pembelajaran cerita rakyat terdapat dalam silabus pada $\begin{array}{lll}\text { kompetensi dasar } & \text { (KD) } 3.7\end{array}$ mengidentifikasi nilai-nilai dan isi yang terkandung dalam cerita rakyat (hikayat) baik lisan maupun tulis dan 4.7 menceritakan kembali isi cerita rakyat (hikayat) yang didengar dan dibaca.

\section{SIMPULAN}

Dalam keenam kumpulan carita rakyat Ogan Komering Ilir hanya lima cerita rakyat yang terdapat tujuh bentuk arketipe. ke lima cerita rakyat tersebut yaitu Putri 
Jari Sakti, Cinta Juliah Putri Ningrat, Si Seman Lempuing, Putri Gelam, dan Keadilan bagi Pangeran Batun. Dan ke tujuh bentuk arketipe yaitu Pesona (Topeng), bayangan (shadow), Anima, Ibu Agung, Orang Tua yang Bijak, Hero, dan Diri (self).Dari hasil analisis pada ketujuh bentuk arketipe terdapat 30 kutipan. Berkaitan denganpembelajaran, cerita rakyat terdapat pada silabus dan RPP yaitu pada kompetensi dasar (KD) 3.7 mengidentifikasi nilai-nilai dan isi yang terkandung dalam cerita rakyat (hikayat) baik lisan maupun tulis dan 4.7 menceritakan kembali isi cerita rakyat (hikayat) yang didengar dan dibaca. Dalam pembelajaran, kumpulan cerita rakyat Ogan

Komering Ilir dapat dijadikan sebagai materi pembelajaran, karena dalam setiap kumpulan cerita rakyat terdapat bayangan-bayangan leluhur yang disebut dengan arketipe yang muncul dalam ketidaksadaran kolektif pada setiap manusia. Kumpulan cerita rakyat ogan komeringi ilir sangat tepat dijadikan materi pembelajaran, karena peserta didik dapat mempelajari berbagai bentuk arketipe di dalamnya yaitu arketipe dalam bentuk perilaku atau sifat yang dimiliki manusia.

\section{SARAN}

Setelah dilakukan penelitian dengan judul "Arketipe dalam kumpulan cerita rakyat OKI dan implementasi pembelajaran bahasa Indonesia di SMA" dan peneliti menyadari bahwa terdapat kelemahan dalam penelitian ini. Oleh sebab itu, diharapkan agar menambah wawasan mengenai pembelajaran sastra terutama pada cerita rakyat, serta disarankan pada peneliti selanjutnya untuk menggunakan cerita rakyat lain dan menggunakan teori lainnya juga.

\section{DAFTAR PUSTAKA}

Noermanzah. 2020. Bahasa sebagai Alat Komunikasi, Citra Pikiran, dan Kepribadian. Jurnal:

Universitas Bengkulu.

Samardi, L.G. 2009. Kajian Strukturalisme dan Nila Edukatif dalam Cerita Rakyat Kabupaten Klaten. Jurnal: Universitas Sebelas Maret Surakarta.

Septiarini, T,. Sembiring, H. R. 2017. Kepribadian Tokoh dalam Novel Mencari Perempuan yang Hilang (Kajian Psikologi Carl Gustav Jung). Jurnal: Universitas Negeri Jakarta. 
Alia, Tri Wulan Dari

Syahdi, Irawan. 2016. Analisis

Legenda Siti Payung. Jurnal: Balai Arketipe dalam Cerita Rakyat Bahasa Aceh. 